OPEN ACCESS

Edited by:

Paul J. Brindley,

George Washington University,

United States

Reviewed by:

Longxian Zhang,

Henan Agricultural University, China

Quan Liu,

Institute of Military Veterinary,

Academy of Military Medical Sciences

(AMMS), China

Ziguo Yuan,

South China Agricultural University,

China

*Correspondence:

Xue Bai

namiya23@163.com

Mingyuan Liu

liumy@jlu.edu.cn;

liumy36@163.com

tThese authors have contributed equally to this work.

Specialty section:

This article was submitted to

Infectious Diseases,

a section of the journal

Frontiers in Microbiology

Received: 15 May 2017 Accepted: 07 September 2017 Published: 21 September 2017

Citation:

$X u$ N, Liu X, Tang B, Wang L, Shi HN, Boireau P, Liu M and Bai $X$

(2017) Recombinant Trichinella pseudospiralis Serine Protease Inhibitors Alter Macrophage Polarization In Vitro

Front. Microbiol. 8:1834. doi: 10.3389/fmicb.2017.01834

\section{Recombinant Trichinella pseudospiralis Serine Protease Inhibitors Alter Macrophage Polarization In Vitro}

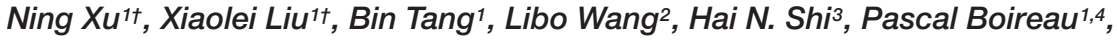 \\ Mingyuan Liu' ${ }^{1,5 *}$ and Xue Bai ${ }^{1 *}$
}

\begin{abstract}
${ }^{1}$ Key Laboratory of Zoonosis Research, Ministry of Education, Institute of Zoonosis, College of Veterinary Medicine, Jilin University, Changchun, China, ${ }^{2}$ Yunnan Institute of Parasitic Diseases, Puer, China, ${ }^{3}$ Mucosal Immunology Laboratory, Pediatric Gastroenterology Unit, Massachusetts General Hospital, Boston, MA, United States, ${ }^{4}$ Laboratory for Animal Health, ANSES, INRA, ENVA, Université Paris-Est, Champs-sur-Marne, France, ${ }^{5}$ Jiangsu Co-innovation Center for Prevention and Control of Important Animal Infectious Diseases and Zoonoses, Yangzhou, China
\end{abstract}

During parasite infection, serine protease inhibitors secreted by parasites play important roles in suppressing host defenses. However, the mechanism of immune regulation is unclear. In this study, a serpin gene from Trichinella pseudospiralis, named Tp-Serpin, was cloned and expressed, in order to reveal its role in the regulation of the host immune response in T. pseudospiralis infection. The results showed that Tp-Serpin encodes a $43 \mathrm{kDa}$ protein that was recognized by serum from T. pseudospiralis infected mice at 60 days post-infection (dpi). Tp-Serpin was found to be expressed at all developmental stages of $T$. pseudospiralis. Inhibitory activity analysis showed that recombinant $T p$-Serpin ( $r T p$-Serpin) effectively inhibited the hydrolytic activity of porcine pancreatic elastase (elastase $P$ ), human neutrophil elastase (elastase $H$ ), and mouse mast cell protease-1, but showed little inhibitory for human neutrophil cathepsin G (cathepsin G). Furthermore, rTp-Serpin induced polarization of macrophages toward the alternatively activated phenotype (M2) alone by activation of the signal transducer and activator of transcription 3 signaling pathway, and inhibited lipopolysaccharide-induced classically activation (M1) in vitro. These data preliminarily demonstrate that Tp-Serpin may play an important role in the immunoregulation of $T$. pseudospiralis infection by activating the M2-polarized signaling pathway.

Keywords: Trichinella pseudospiralis, serine proteinase inhibitors, alternatively activated macrophages, inhibitory activity

\section{INTRODUCTION}

Trichinella is an intracellular parasite of skeletal muscle that can infect a wide variety of mammalian species and some carnivorous birds. Hosts are infected by ingestion of animal tissues containing infective larvae (Arora et al., 2017). Trichinellosis has been regarded as an emerging or re-emerging widespread food-borne disease (Gottstein et al., 2009; Rostami et al., 2017). Trichinella, as with other helminths, can ensure its survival by modulating the host immunological response (SofronicMilosavljevic et al., 2015). Induction of host immunosuppression is an important strategy for 
pathogens to invade their hosts and is a common characteristic of helminth infections. Among the helminths, Trichinella is one of the few parasites with the extremely strong ability to induce host immune suppression (Bruschi, 2002). Recently, several studies have shown that Trichinella infection can alleviate or inhibit various immune-related diseases, including type I diabetes, experimental allergic encephalitis, inflammatory bowel disease, and airway allergic inflammation (Park et al., 2011; Wang et al., 2016).

Excretory-secretory proteins (ESPs) released by Trichinella contain numerous functional proteins, which induce strong immunosuppression in the first 2 weeks of the infection and Th2 polarized and alternatively activated macrophages (M2) respond throughout the whole Trichinella infectious process (Ilic et al., 2012). Moreover, the ESPs of Trichinella larvae significantly inhibit lipopolysaccharide (LPS)-induced macrophages activity, which play crucial roles in host immune responses against various pathogens (Bai et al., 2012). These studies show that Trichinella can regulate the host immune response by encoding immune regulator to interfere with immune recognition. Unfortunately, the key immune regulator of Trichinella is still unknown.

Serine protease inhibitors play a variety of important biological roles by controlling endogenous and exogenous proteolytic activities involved in coagulation, inflammation, and apoptosis (Heit et al., 2013). In helminths, serpins play a key role in inhibiting blood coagulation, resisting host protease damage, and also serve as targets for escaping host immune attack (Molehin et al., 2012). These inhibitors also have been shown to play key roles in host immune evasion, and hence the suggestion that helminth serpins may have evolved for the purpose of limiting host immune activation by interfering with host immunomodulatory signals (Molehin et al., 2014). In previous studies, part of a gene encoding serpins from Trichinella spiralis and other helminths have been discovered and have shown biological activity (Molehin et al., 2014; Moreira et al., 2014; Zhang et al., 2016). However, the immunomodulatory function of serpins from Trichinella pseudospiralis has not yet been reported.

There are nine species and three genotypes in the genus Trichinella; some of them develop in muscle cells that become encapsulated (e.g., T. spiralis), while others develop in cells and not encapsulated (e.g., T. pseudospiralis) (Pozio and Zarlenga, 2013). As it is not encapsulated, T. pseudospiralis should be more susceptible to the host immune attack. Relative to T. spiralis, T. pseudospiralis induces stronger immunosuppression, to ensure survival in muscle cells (Asano et al., 2016). In the present study, a high-frequency gene encoding a serine protease inhibitor protein from $T$. pseudospiralis (Tp-Serpin) was identified. Expression of Tp-Serpin has been detected both in ESPs and crude parasite antigen preparations during all development stages of T. pseudospiralis suggested that Tp-Serpin may play an important role in T. pseudospiralis infection. In order to analyze the role of $T p$-Serpin in regulating the host immune response, recombinant Tp-Serpin (rTp-Serpin) was successfully produced in Escherichia coli and its function in regulating macrophages polarization was determined.

\section{MATERIALS AND METHODS}

\section{Ethics Statement}

Animals were treated in strict accordance with the National Institutes of Health guidelines (publication no. 85-23, revised 1996). Studies involving animals were reviewed and approved by the Ethical Committee of Jilin University affiliated to the Provincial Animal Health Committee, Jilin Province, China (Ethical Clearance number IZ-2009-08).

\section{Cell Culture, Animals, Parasites, and Excretory-Secretory Proteins (ESPs)}

BALB/c mice (female, 6-8 weeks old) were purchased from Shanghai SLAC Company. The murine macrophage cell line J774A.1 was purchased from American Type Culture Collection and cultured in RPMI 1640 medium containing 10\% heat inactivated fetal bovine serum (FBS) at $37^{\circ} \mathrm{C}$ in a $5 \% \mathrm{CO}_{2}$ atmosphere.

Trichinella pseudospiralis (ISS13) muscle larvae (ML) were recovered from BALB/c mice at 35 days post-infection (dpi) by pepsin- $\mathrm{HCl}$ digestion. Adult worms at day 3 (Ad3) and new born larvae (NBL) were recovered as previously described (Robinson et al., 2007). The ML, Ad3, and NBL were incubated in pre-warmed serum-free RPMI medium 1640 with $2 \%$ antibiotics (penicillin and streptomycin) at $37^{\circ} \mathrm{C}$ and with $5 \%$ atmospheric $\mathrm{CO}_{2}$ for $24 \mathrm{~h}$. Following incubation the supernatant was collected, dialyzed, and concentrated in using Ultra-15 $3 \mathrm{~K}$ centrifugal filters (Millipore, United states) (Cwiklinski et al., 2009). All parasites and the concentrated ESPs were stored at $-80^{\circ} \mathrm{C}$ for further use.

\section{Molecular Characterization and Phylogenetic Analysis}

The amino acid sequence of Tp-Serpin was submitted to https:// www.ncbi.nlm.nih.gov/Structure/cdd/wrpsb.cgi to predict its putative structure and reactive-site loop. Phylogenetic relationships among serpins based on $T p$-Serpin homologs were constructed using MEGA7.

\section{Cloning, Expression, and Purification of Recombinant Tp-Serpin (rTp-Serpin)}

Total RNA from ML was collected (Qiagen, Germany) and reverse-transcribed into cDNA (Stratagene, United States). The Tp-Serpin sequence (GenBank: JF764789.1) was amplified from the cDNA of ML by PCR (forward primer, $5^{\prime}$-CGC ATA TGC GAT GTC GTC CGT CCG TCA ATT TCG AC-3', containing the Nde I restriction site; reverse primer, 5'-CCG $\underline{\text { CTC GAG }}$ ACC ACG ATA ACT TCC CAT GAA C-3', containing the Xho I restriction site). The PCR products were sub-cloned into pMD19-T-Simple vector (Takara, Dalian, China) for sequencing. The cloned gene was excised by digestion with Nde I/Xho I and sub-cloned into the pCold I prokaryotic expression vector. After transformation into E. coli Rosetta gami (DE3) cells (Novagen, Germany), rTp-Serpin expression was induced with $0.3 \mathrm{mM}$ IPTG for $16 \mathrm{~h}$ at $18^{\circ} \mathrm{C}$. The $\mathrm{rTp}$-Serpin was purified using HiTrap ${ }^{\mathrm{TM}}$ affinity columns (GE healthcare, United States) 
according to the manufacturer's instruction. The purified rTp-Serpin was analyzed by $12 \%$ SDS-PAGE and Western blot using serum from mice infected with T. pseudospiralis for $60 \mathrm{dpi}$ and a HRP-conjugated goat anti-mouse IgG as the secondary antibody (Tang et al., 2015). Western blots were developed using the ECL plus Western blotting detection system (GE Healthcare Buckinghamshire, United Kingdom).

\section{Production of Polyclonal Antibodies Against rTp-Serpin}

Six-week-old BALB/c mice were first injected intraperitoneally with approximately $100 \mu \mathrm{g}$ of purified $\mathrm{rTp}$-Serpin mixed 1:1 (v/v) with complete Freund's adjuvant (CFA). Additional injections of $100 \mu \mathrm{g}$ of protein with incomplete Freund's adjuvant (IFA) were administered to the animals 2 weeks later. Preimmune serum was collected prior to the immunizations. Two weeks after the last injection, serum samples were collected, titrated, and stored at $-20^{\circ} \mathrm{C}$.

\section{Western Blot Analysis of Tp-Serpin in T. pseudospiralis Developmental Stages}

Trichinella pseudospiralis worms and the ESPs of NBL, Ad3, and ML, respectively, were prepared as previously described. Equal amounts of samples $(20 \mu \mathrm{g}$ per well, ESPs, and crude protein of NBL, Ad3, and ML) were electrophoresed on 12\% SDS-PAGE gel and electro-transferred to PVDF (Immobilon, Millipore, United States). Non-specific binding sites were blocked by immersing the membranes in 5\% skim milk in phosphatebuffered saline (PBS) overnight at $4^{\circ} \mathrm{C}$. After washing three times in PBS containing 0.1\% Tween-20 (PBST), membranes were incubated with mouse anti-rTp-Serpin serum (dilutions 1:200 in PBS) for $1 \mathrm{~h}$ at $37^{\circ} \mathrm{C}$, and subsequently washed three times in PBST. The membranes were then incubated with HRP-conjugated goat anti-mouse IgG for $1 \mathrm{~h}$ at $37^{\circ} \mathrm{C}$ (diluted 1:5000 in PBS) (Tang et al., 2015). After washing several times with PBST, the peroxidase activity was detected as previously described.

\section{Inhibitory Activity Assay}

Single-stage kinetic assays were used to characterize the inhibitory activity of $\mathrm{r} T p$-Serpin against four serine proteases (Kang et al., 2010). Increasing concentrations of rTp-Serpin (0-15 g/l) were pre-incubated with each of the enzymes in $50 \mathrm{mM}$ PBS ( $\mathrm{pH} 7.4$ ) for $30 \mathrm{~min}$ at $25^{\circ} \mathrm{C}$ followed by the addition of the appropriate chromogenic substrate for $10 \mathrm{~min}$ at $25^{\circ} \mathrm{C}$. The concentrations (expressed as final concentrations) of enzyme/substrate were shown in Table 1 (final volume of $200 \mu \mathrm{l}$ in individual wells of a 96-well microtiter plate). Finally, absorbance changes at $405 \mathrm{~nm}$ were monitored over $5 \mathrm{~min}$ using a Kinetic Microplate Reader to analyze the hydrolytic activity of the proteases and evaluate the inhibitory activity of recombinant proteins. Reactions without recombinant protein or with phenylmethanesulfonyl (PMSF; Boehringer, Mannheim, Germany) fluoride were employed as negative and positive controls, respectively.

\section{In Vitro Treatment of Macrophages}

The murine macrophage J774A.1 cells were counted and adjusted to a density of $2 \times 10^{5}$ cells $/ \mathrm{ml}$ before being cultured in a 96-well cell culture plate (Costar). Cells were stimulated with 1-25 $\mu \mathrm{g} / \mathrm{ml}$ $\mathrm{rTp}$-Serpin at $37^{\circ} \mathrm{C}$ for $48 \mathrm{~h}$ in the presence of $5 \% \mathrm{CO}_{2}$, followed by the addition of $10 \mu \mathrm{l} /$ well Cell Counting Kit-8 (CCK-8; Dojindo Laboratories, Kumamoto, Japan) solution. Plates were then incubated for $4 \mathrm{~h}$ in the dark and the absorbance of the samples at $450 \mathrm{~nm}$ was measured.

After the macrophage viability assay, macrophages were treated with $r T p$-Serpin alone or together with LPS in order to determine the role of $\mathrm{rTp}$-Serpin in macrophage polarization. In the macrophage polarization tests, cells were seeded at a density of $1 \times 10^{6}$ cells $/ \mathrm{ml}$ and cultured in a 12 -well cell culture plates. The cells were treated with $\mathrm{r} T p$-Serpin $(5 \mu \mathrm{g} / \mathrm{ml})$ alone or co-treated with LPS (100 ng/ml) for $24 \mathrm{~h}$. LPS (100 ng/ml) or IL-4 $(10 \mathrm{ng} / \mathrm{ml})$ treated cells were used as positive controls. Cell culture medium treated cells were used as a negative control. After $24 \mathrm{~h}$ treatment, the cells and conditioned media were collected to be analyzed for polarization activity.

\section{Flow Cytometry}

Treated macrophages were washed in PBS and adjust to $1 \times 106$ cells/100 $\mu \mathrm{l}$ PBS with $1 \%$ FBS. Cells were incubated with antibodies against CD206 (PE-conjugated, $0.5 \mu \mathrm{g}$ per million cells in $100 \mu \mathrm{l}$ volume) and CD16/32 (FITC-conjugated, $1.0 \mu \mathrm{g}$ per million cells in $100 \mu \mathrm{l}$ volume) (BioLegend, United States) for surface marker analysis of the polarized macrophages. Cell suspensions were incubated with the antibodies for $30 \mathrm{~min}$ at $4^{\circ} \mathrm{C}$ and washed three times with PBS. Samples were analyzed using a BD FACSCalibur Flow Cytometer and the results were analyzed using FlowJo software (Tree star Inc., Ashland, OR, United States).

\section{Real-Time PCR}

Treated macrophages were washed with RPMI 1640 medium. RNA was extracted and purified (Qiagen, Germany) and converted to cDNA (Stratagene, United States) according to the manufacturer's instructions. Quantitative real-time PCR was conducted using FastStart Universal SYBR Green Master (Rox) reagents (Roche Diagnostics, Indianapolis, IN, United States) and a 7500 real-time PCR machine (Applied Biosystems, Foster City, CA, United States). The reaction conditions were: $1,95^{\circ} \mathrm{C}$ for $10 \mathrm{~min} ; 2,40$ cycles of $95^{\circ} \mathrm{C}$ for $15 \mathrm{~s}, 56^{\circ} \mathrm{C}$ for $1 \mathrm{~min}$,

TABLE 1 | Enzyme/substrate used for rTp-Serpin inhibitory activity assay.

\begin{tabular}{ll}
\hline Enzyme & Substrate \\
\hline Porcine pancreatic elastase & N-succinyl-Ala-Ala-Ala-p-nitroanilide \\
(elastase P, 2 nM, Sigma Aldrich) & $(100 \mathrm{M}$, Sigma Aldrich) \\
Human neutrophil elastase & N-succinyl-Ala-Ala-Pro-Leu-p-nitroanilide \\
(elastase H, 17 nM, Sigma Aldrich) & $(100 \mathrm{M}$, Sigma Aldrich) \\
Human neutrophil cathepsin G & N-succinyl-Ala-Ala-Pro-Phe-pnitroanilide \\
(cathepsin G, 220 nM, Sigma Aldrich) & $(100 \mathrm{M}$, Sigma Aldrich) \\
Mouse mast cell protease-1 & $\mathrm{N}$-succinyl-Ala-Ala-Pro-Phe-pnitroanilide \\
(mMCP-1, 3 nM, Sigma Aldrich) & $(100 \mathrm{M}$, Sigma Aldrich)
\end{tabular}


TABLE 2 | Primers used for quantitative real-time PCR.

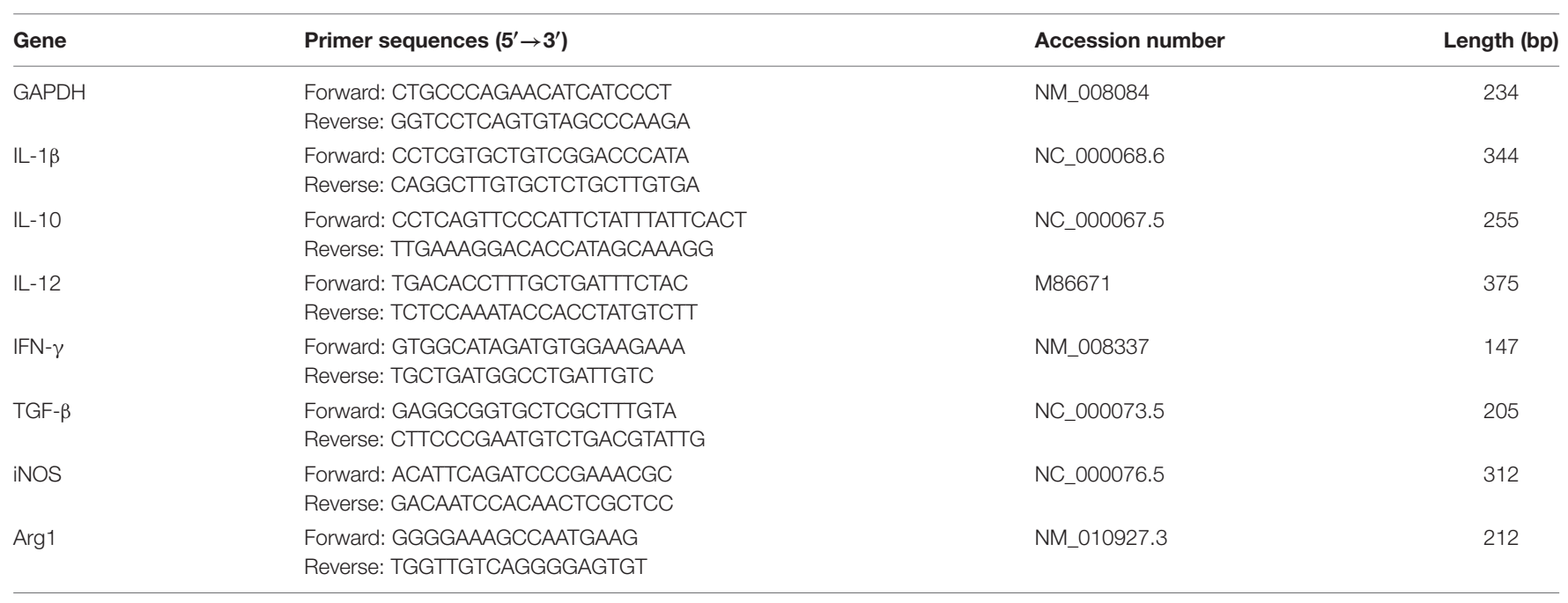

and $72^{\circ} \mathrm{C}$ for $1 \mathrm{~min}$, which were concluded by a melting curve analysis. Fold changes of gene expression were calculated using the $2^{-\Delta \Delta C_{\mathrm{T}}}$ method. Primer sequences are listed in Table 2 (Bai et al., 2012).

\section{Cytokine Assays}

To assay cytokine production levels, supernatants from treated macrophages were collected. Levels of pro-inflammatory (IFN- $\gamma$, IL-1 $\beta$ ) and anti-inflammatory cytokines (IL-10, TGF- $\beta$ ) production were analyzed using the murine cytokine ELISA Kit (eBioscience, United States). Cytokine concentrations were determined in duplicate and at a dilution that fell in the middle of the standard curve according to the manufacturer's protocol. All measurements were performed in triplicate. The average absorbance at $450 \mathrm{~nm}$ was determined for each sample and was used to calculate cytokine concentrations as picograms per milliliter (pg/ml).

\section{Analysis of STAT3/JAK2 Phosphorylation and the Relationship with IL-10 Levels}

In the signaling pathway analysis, J774A.1 macrophages $\left(1 \times 10^{6}\right.$ cells/well) were cultured in 6-well plates for $24 \mathrm{~h}$ and were treated with different concentrations of $\mathrm{rTp}$-Serpin $(0.5,1$, and $2 \mu \mathrm{g} / \mathrm{ml})$ or cell culture medium for $2 \mathrm{~h}$. The conditioned medium was collected to assay IL-10 levels by ELISA as described previously. Cells were then collected, washed three times with ice-cold PBS, and re-suspended in PBS mixed with $1 \mathrm{mM}$ PMSF (Boehringer, Mannheim, Germany). After incubation on ice for $30 \mathrm{~min}$, protein concentrations were measured with the Pierce BCA Protein Assay Kit (Illinois, United States). For the analysis of signal transducer and activator of transcription 3 (STAT3)/JAK2 phosphorylation, $30 \mu \mathrm{g}$ of total cellular protein was analyzed by Western blot with rabbit anti-mouse STAT3/JAK2 antibody, rabbit anti-mouse p-STAT3/JAK2 antibody (Santa, CA, United States), and $\beta$-actin (mouse monoclonal Ab6276), followed by a HRP-conjugated goat anti-rabbit secondary antibody (1:20,000). STAT3/JAK2 activation was detected as previously described.

\section{Statistical Analysis}

All results were expressed as mean \pm SD. Statistical analysis was performed using the GraphPad Prism 5 for Windows. Oneway and two-way analysis of variance (ANOVA) was used to compare statistical differences at different conditions. $P$-values are expressed as ${ }^{*} p<0.05$ and ${ }^{* *} p<0.01$ in comparison with the control group or LPS treatment group.

\section{RESULTS}

\section{Molecular Characterization of the Tp-Serpin}

The Tp-Serpin open-reading frame was found to $1134 \mathrm{bp}$ and encoded 378 amino acids. Based on the structural prediction, Tp-Serpin consists of $60.71 \% \alpha$-helices and $39.29 \% \beta$-sheets, and the solvent-exposed reactive center loop is near the C-terminus (Figures 1A,C). The phylogenetic relationship of $T p$-Serpin with serpin family proteins was analyzed by comparing amino acid sequences. The results indicated that $T p$-Serpin is genetically related to $T s$-Serpin, from $T$. spiralis, and are more closely related to nematode serpins than vertebrate serpins (Figure 1B).

\section{Cloning, Expression, and Purification of Recombinant Tp-Serpin (rTp-Serpin)}

The full-length $T p$-Serpin gene was obtained, cloned into the prokaryotic expression vector pCold I, and transformed into E. coli Rosetta gami (DE3). The recombinant protein (rTp-Serpin) was expressed in $E$. coli as a soluble protein with a relative molecular mass of about 43k Da (Figure 2A), which was consistent with the estimated molecular mass of the deduced amino acid sequence of $T p$-Serpin. The purified rTp-Serpin was recognized specifically by serum 

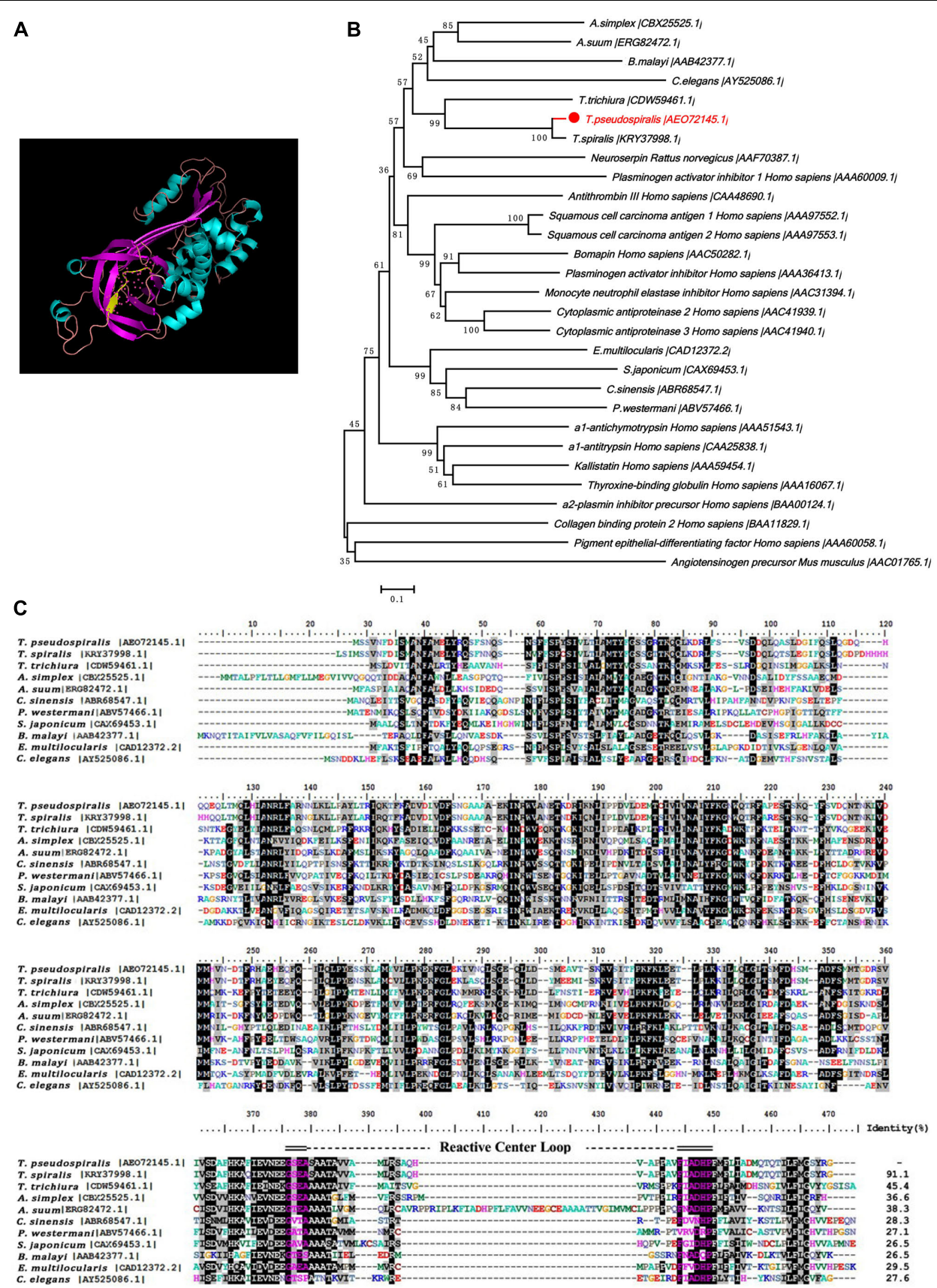

FIGURE 1 | Putative structures and the phylogenetic relationship of Tp-Serpin to other serpin homologs. (A) Structure of Tp-Serpin. The reactive-site loop of the serpins is shown as a yellow strand. (B) Phylogenetic tree of Tp-Serpin and other serine proteinase inhibitors. (C) Amino acid sequences of Tp-Serpin in the region of the reactive-site loop and comparison with other nematode serpin proteins. The reactive-site loop is shaded in blue.

from mice infected with T. pseudospiralis at $60 \mathrm{dpi}$ (Figure 2B).

\section{Tp-Serpin Expression in All Life Stages of T. pseudospiralis}

$T p$-Serpin expression was detected throughout all examined developmental stages, including ML, Ad3, and NBL (Figure 2C). To investigate the expression pattern of Tp-Serpin, the ESPs and crude parasite antigens from T. pseudospiralis at all developmental stages were analyzed by Western blotting. AntirTp-Serpin serum recognized an abundant amount of $T p$-Serpin in a band at approximately $43 \mathrm{kDa}$ in crude parasite antigen, and ESPs also showed a weak positive reaction (Figure 2C). This suggests that $T p$-Serpin was expressed at all developmental stages of T. pseudospiralis, and was a secretory protein, which play an important role in regulate the host immune response. 


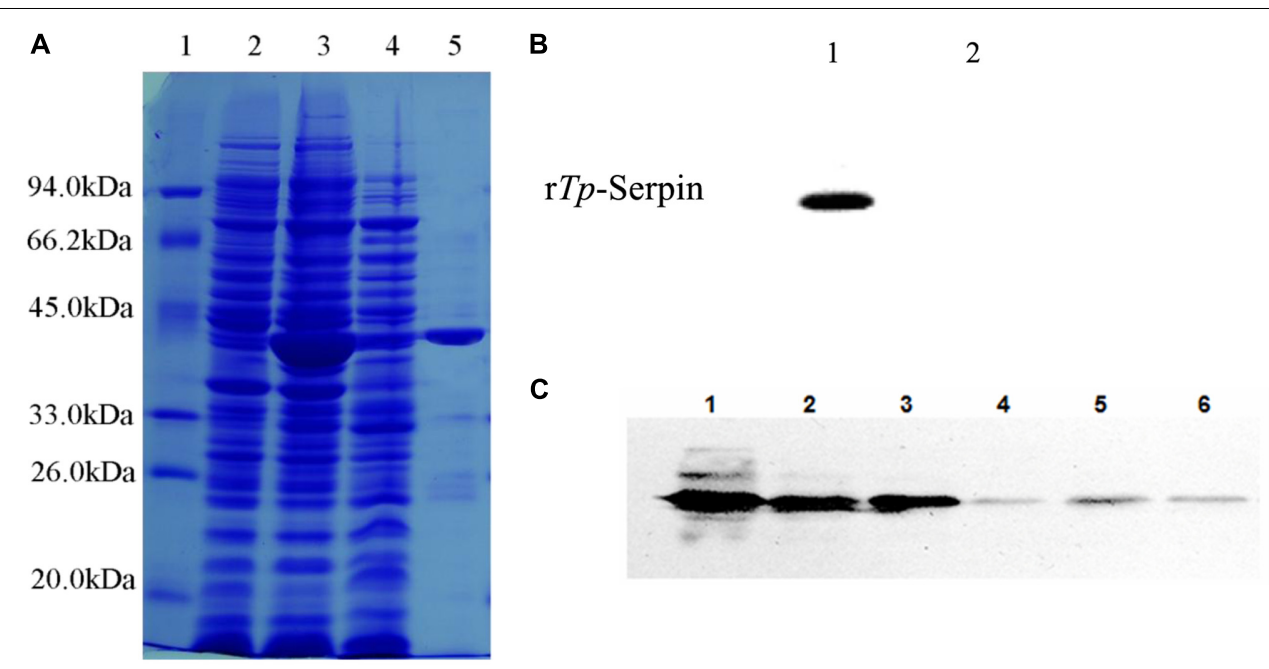

FIGURE 2 | Analysis of purified recombination Tp-Serpin (rTp-Serpin) and the expression pattern of Tp-Serpin in T. pseudospiralis developmental stages. (A) SDS-PAGE of purified rTp-Serpin M: protein standard; 1: total protein expressed without induction; 2: total protein induced by $0.3 \mathrm{mM}$ IPTG; 3 : soluble protein induced by $0.3 \mathrm{mM} \mathrm{IPTG}$; and 4: purified rTp-Serpin. (B) Antigenicity of $\mathrm{rTp}$-Serpin as determined by Western blot analysis. 1: sera of mice at $60 \mathrm{dpi}$ and 2: preimmune sera of mice. (C) Western bolt analysis of Tp-Serpin in T. pseudospiralis developmental stages. 1: T. pseudospiralis-AD3 crude parasite antigen, 2: T. pseudospiralis-NBL crude parasite antigen, 3: T. pseudospiralis-ML crude parasite antigen, 4: T. pseudospiralis-AD3 ESPs, 5: T. pseudospiralis-NBL ESPs, and 6: T. pseudospiralis-ML ESPS.

A

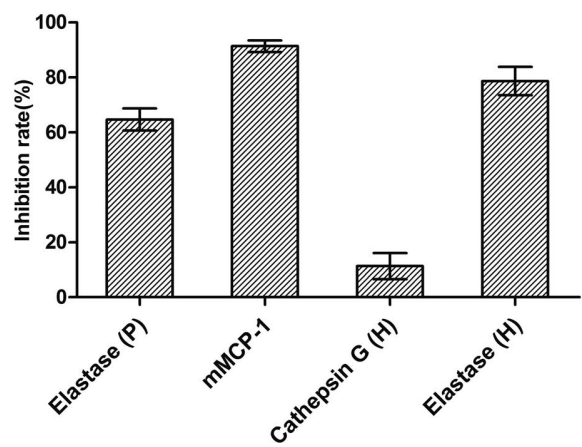

B

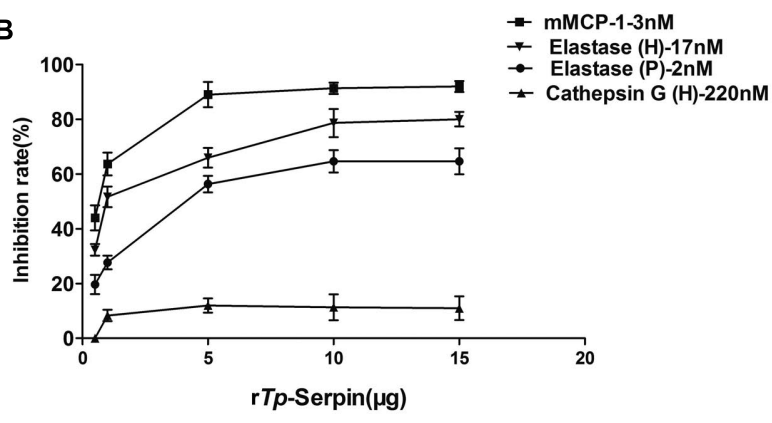

FIGURE 3 | Inhibitory activity assay of rTp-Serpin against different proteases. (A) Inhibitory activity assay of rTp-Serpin on porcine pancreatic elastase (elastase P), human neutrophil elastase (elastase $\mathrm{H}$ ), human neutrophil cathepsin $\mathrm{G}$ (cathepsin $\mathrm{G}$ ), and mouse mast cell protease-1 (mMCP-1). (B) Concentration-dependent inhibition profiles of elastase $\mathrm{P}$, elastase $\mathrm{H}$, cathepsin $\mathrm{G}$, and $\mathrm{mMCP}-1$.

\section{Inhibitory Activity of rTp-Serpin In Vitro}

To study the potential inhibitory activity of rTp-Serpin, inhibition of a series of serine proteases with different substrate specificity was tested. Inhibitory activity assays showed that rTp-Serpin effectively inhibited the hydrolysis activity of elastase $(\mathrm{P} / \mathrm{H})$ and mouse mast cell protease-1 (mMCP-1), but showed little inhibitory activity against cathepsin G (Figure 3A). In addition, the inhibitory activity of $\mathrm{r} T p$-Serpin appeared to be dose dependent (Figure 3B).

\section{The Viability of Macrophages Treated with rTp-Serpin In Vitro}

To further investigate the function of rTp-Serpin in the polarization of J774A.1 macrophages, a CCK-8 assay was performed. As shown in Figure 4, at low concentrations $(1-5 \mu \mathrm{g} / \mathrm{ml})$, rTp-Serpin did not affect the viability of macrophages, while it had a significant difference in high concentration ( $p<0.05,10 \mu \mathrm{g} / \mathrm{ml} ; p<0.01,15-25 \mu \mathrm{g} / \mathrm{ml})$. In view of the above results, the concentration of recombinant protein required for macrophage differentiation was $5 \mu \mathrm{g} / \mathrm{ml}$.

\section{Phenotype Analysis of Macrophage by rTp-Serpin}

In flow cytometry analysis, the percentage of $\mathrm{CD} 206^{+}$ macrophage cells was found to be significantly increased after incubation with $\mathrm{rTp}$-Serpin alone compared with the control group ( $p<0.05$, Figure $\mathbf{5 A}$ ). On the other hand, 


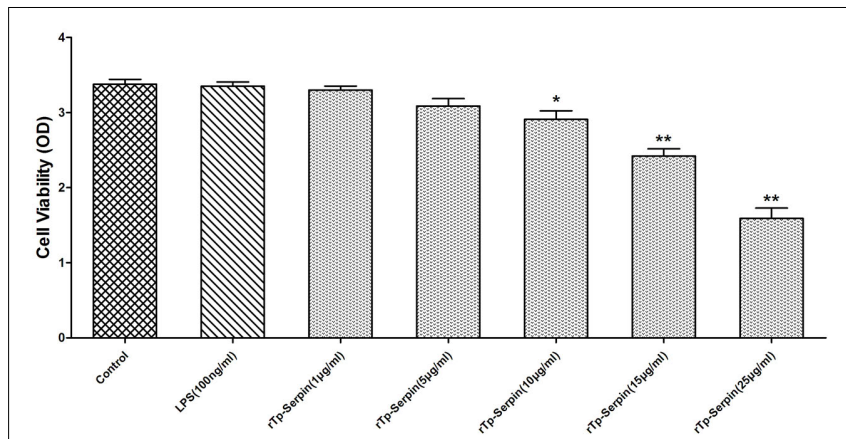

FIGURE 4 | The viability of J774A.1 macrophages treated with rTp-Serpin. Effect of different concentration $r T p$-Serpin $(1-25 \mu \mathrm{g} / \mathrm{ml})$ on the viability of J774A.1 macrophages. Results are shown as the mean \pm standard deviation (SD) for at least five independent experiments for each group. Significant differences were as follows: ${ }^{*} p<0.05 ;{ }^{*} p<0.01$.

rTp-Serpin significantly suppressed the percentage of CD16/32 macrophages induced by LPS compared with the LPS group $(p<0.01$, Figure 5A).

In SYBR green I real-time PCR analysis, the mRNA levels of pro-inflammatory cytokines (IFN- $\gamma$, IL-1 $\beta$, and IL-12) were suppressed by $\mathrm{rTp}$-Serpin in LPS-treated macrophages compared with the LPS group $(p<0.05$, IL-12; $p<0.01$, IFN- $\gamma$ and IL-1 $\beta$; Figure 5B). Additionally, the level of iNOS was inhibited in a similar fashion to the pro-inflammatory cytokines (Figure 5B). Furthermore, in the tests of macrophages treated with $r T p$-Serpin alone, the expression of anti-inflammatory cytokines (IL-10, TGF- $\beta$ ) and marker effector molecules of M2 (Arg1) was significantly up-regulated ( $p<0.01$, Figure 5C). Moreover, the level of iNOS showed no significant change following stimulation with rTp-Serpin (Figure 5C). Similarly, in the ELISA test, the expression levels of pro-inflammatory (IFN- $\gamma$, IL-1 $\beta$ ) and anti-inflammatory cytokines (IL-10, TGF- $\beta$ ) demonstrated the same biological effect $(p<0.01$, IL-1 $\beta$ and IL-10; $p<0.05$, IFN- $\gamma$ and TGF- $\beta$; Figures 5B,C). In summary, $\mathrm{r} T p$-Serpin induced polarization of macrophages toward the M2 phenotype, and inhibited LPS-induced M1 polarization in vitro.

\section{rTp-Serpin Activates the JAK2/STAT3 Signaling Pathway}

To determine whether the polarization of macrophages treated by $r T p$-Serpin was secondary to the activation of a specific upstream signaling pathway within the macrophage, phosphorylation of JAK2/STAT3 was evaluated to determine the effect on the activation state of macrophages. Western blot analysis demonstrated a striking phenotypic difference between macrophages treated with different concentrations of rTp-Serpin. The phosphorylation of STAT3 and JAK2 increased with increasing doses of rTp-Serpin (Figure 6A). Unexpectedly, IL-10 levels were not significantly different to the negative control group in low concentration of rTp-serpin $(1-2.5 \mu \mathrm{g} / \mathrm{ml}$, Figure 6B). This indicated that phosphorylation was detected before IL-10 up-regulation.

\section{DISCUSSION}

Parasite serpins play an important role in interference with immune recognition and the immune response in the process of invasion in the body. Studies have shown that the Schistosoma haematobium serpin reduced immunogenicity of the pathogen by binding with human trypsin and evading the host's immune attack (Molehin et al., 2012). In addition, some parasite serine protease inhibitors are involved in embryonic development and reproductive processes, mediated by endogenous modulators that act on the protease (Nagano et al., 2001). In our study, the putative structure of $T p$-Serpin was shown to have a common highly ordered tertiary structure that is shared with all members of the serpin family. The functional domain, known as reactivesite loop, is near the C-terminus and is exposed on the surface of the protein, which traps the protease. In summary, based on a detailed comparison between amino acid sequences of Tp-Serpin and other members of the serpin family, it was concluded that Tp-Serpin has the inhibition activity, which was more closely related to other serpins.

Generally, serpins of parasitic helminthes have strong immunoreactivity and are classified into secretory and intracellular categories (Molehin et al., 2012). In our study, the results showed that the $\mathrm{rTp}$-Serpin was specifically recognized by serum from mice infected with $T$. pseudospiralis for 60 days. $T p$-Serpin induced the humoral immune response in mice and may act as the main protective antigen in the infection process of $T$. pseudospiralis. Analysis of various life-cycle stages of $T$. pseudospiralis for the expression of $T p$-Serpin showed that translation of $T p$-Serpin happened in all periods of T. pseudospiralis development, suggested that $T p$-Serpin may play an important role in the development of T. pseudospiralis. Furthermore, $T p$-Serpin was detected in excretory-secretory proteins (ESPs), indicated that it is an exocrine protein and may function by acting directly on cells or humoral molecules of the host.

Trichinella have the ability to evade the host immune response, which results in forming a long-term infection in the host. At present, two clades of Trichinella have been identified: encapsulated species (T. spiralis) and non-encapsulated species (T. pseudospiralis) (Bruschi et al., 2014). Both of these clades exert strong immunosuppression in order to evade the host immune response. However, as T. pseudospiralis is non-encapsulated it should be more susceptible to host immune attack. Therefore, T. pseudospiralis must produce stronger immunosuppression to live in muscle cells. In both primates and rodents, $T$. pseudospiralis is less pathogenic than T. spiralis, generating considerably less inflammation (due to strong immunosuppression) (Reichard et al., 2015). These differences also extend to the suppression of cellular infiltration and diffuse myopathy (Boonmars et al., 2005). So far, the studies related to the genes involved in T. pseudospiralis immune escape are undefined. However, research on the immune evasion of serine protease inhibitors (Serpins) during the invasion period of other helminths provides some indications (Nagano et al., 2003). In this current study, the hydrolytic activity of trypsin, elastase, and chymotrypsin was significantly inhibited by rTp-Serpin. 

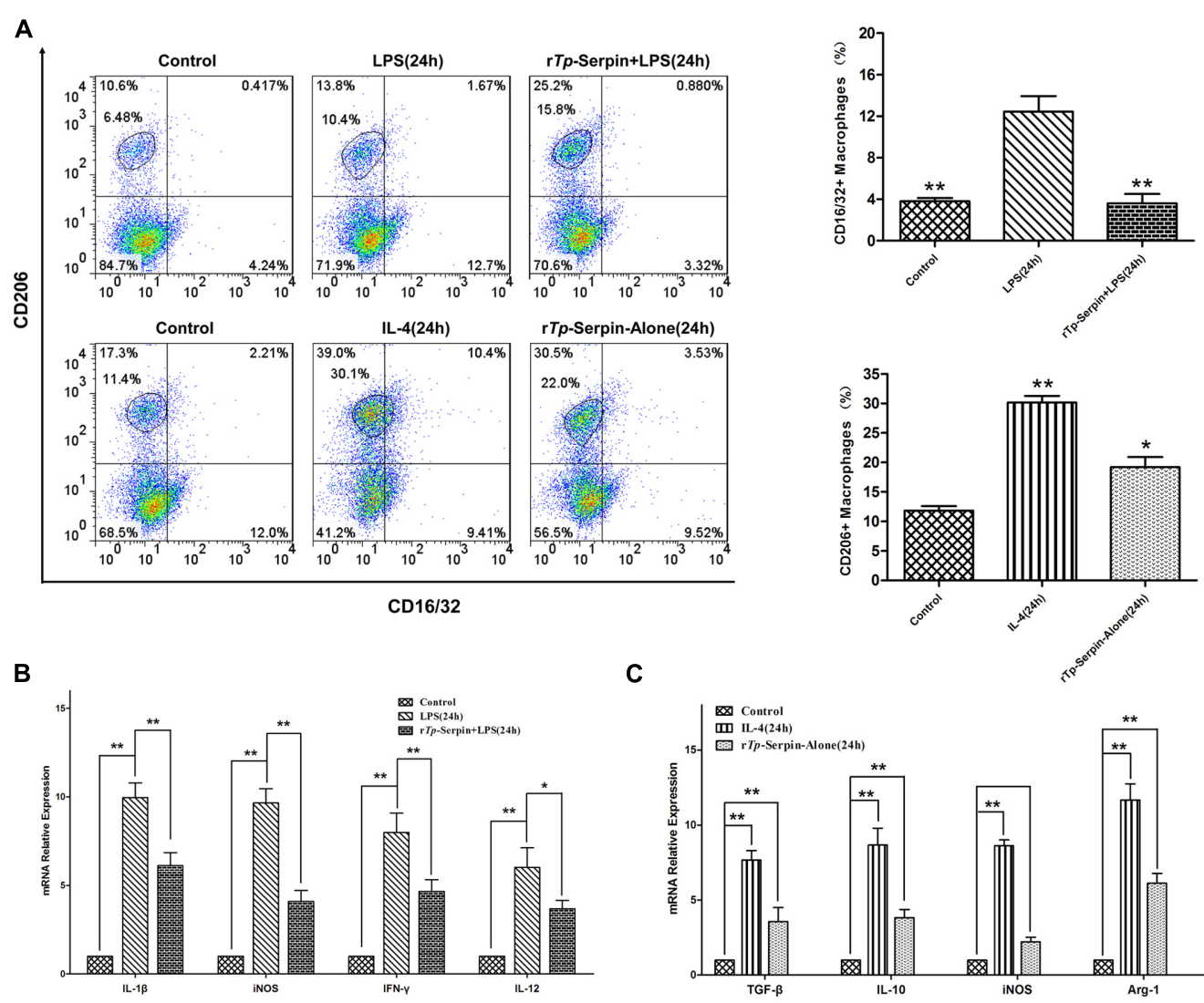

C
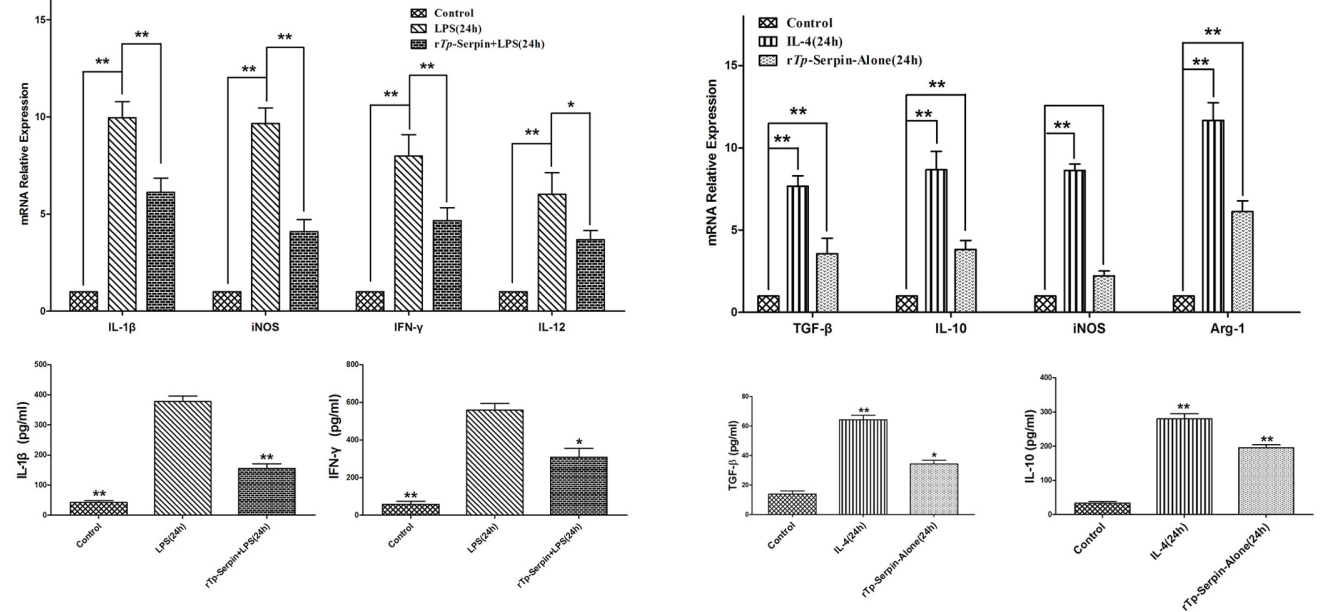

FIGURE 5 | The polarization J774A.1 macrophages treated with rTp-Serpin. (A) Flow cytometry analysis macrophage polarization and expression of CD16/32 (M1) and CD206 (M2) after treatment with rTp-Serpin. (B) Effect of rTp-Serpin on pro-inflammatory cytokines and iNOS expression in LPS-induced J774A.1 macrophages. J774A.1 macrophage cells were treated with $\mathrm{rTp}$-Serpin $(5 \mu \mathrm{g} / \mathrm{ml})+\mathrm{LPS}(100 \mathrm{ng} / \mathrm{ml})$ or LPS $(100 \mathrm{ng} / \mathrm{ml})$ alone for $24 \mathrm{~h}$. (C) Effect of rTp-Serpin on anti-inflammatory cytokines and marker effector molecules (iNOS, Arg1) in J774A.1 macrophages. J774A.1 macrophage cells were treated with $5 \mu \mathrm{g} / \mathrm{ml} \mathrm{rTp}$-Serpin alone or IL-4 $(10 \mathrm{ng} / \mathrm{ml})$ for $24 \mathrm{~h}$. Control group was no treatment/medium alone. Results are shown as the mean $\pm \mathrm{SD}$ for at least three independent experiments for each group. Significant differences are as follows: ${ }^{*} p<0.05 ;{ }^{* *} p<0.01$.

This suggests that $T p$-Serpin may have biological activity and play important function in evasion host immune response in each stage of T. pseudospiralis natural infection by inhibiting the function of enzymes secreted host cell. As elastase $(\mathrm{P})$ and mMCP-1 are located in the digestive tract, the inhibition of digestion enzymes may prevent $T$. pseudospiralis, in the intestinal infection stage, from being damaged. Moreover, $\mathrm{mMCP}-1$ plays a role in chemotaxis of neutrophils and other inflammatory cells and enhances the permeability of intestinal epithelial cells, thereby enabling complement and antibodies into the intestine to kill and exclude parasites (Miller and Pemberton, 2002). Therefore, interaction with $\mathrm{rTp}$-Serpin can offset the immune response and affect the exclusion caused by $\mathrm{mMCP}-1$ and elastase $(\mathrm{P})$ in the intestinal tract. Unlike elastase (P) and mMCP-1, elastase $(\mathrm{H})$ can promote the production of inflammatory cytokines and antibodies, as well as lymphocyte proliferation (Bank and Ansorge, 2001). These positive effects of immune response also help to prevent parasite invasion in the host (Molehin et al., 2012). Thus, by inhibiting the biological activity of elastase $(\mathrm{H}), \mathrm{rTp}$-Serpin may contribute $T$. pseudospiralis ability to evade the body's immune response.

Generally, in response to environmental stimuli, the balance of the Th1/Th2 immune response changes, and macrophage polarization can take place in the appropriate immune response environment, leading to M1 or M2 phenotypes (Gordon, 2003; Biswas and Mantovani, 2010; Sudduth et al., 2013). It is well accepted that parasites can strongly induce M2 polarization (Ramanan et al., 2016; Kim et al., 2017). During the process of 


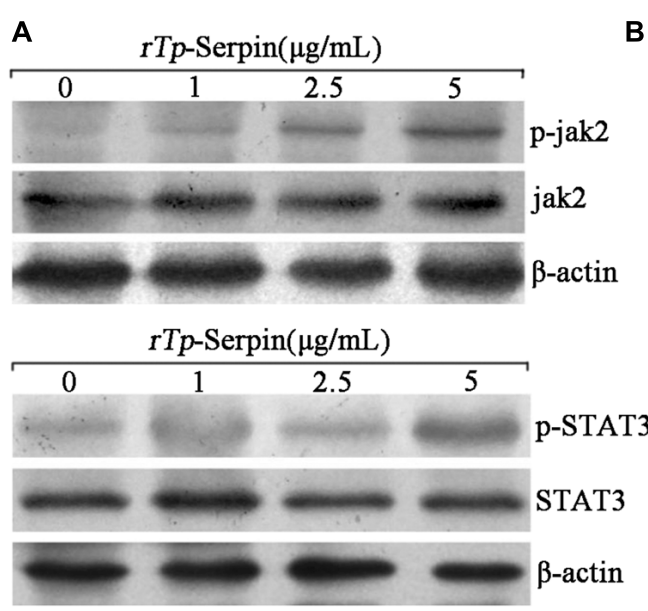

B

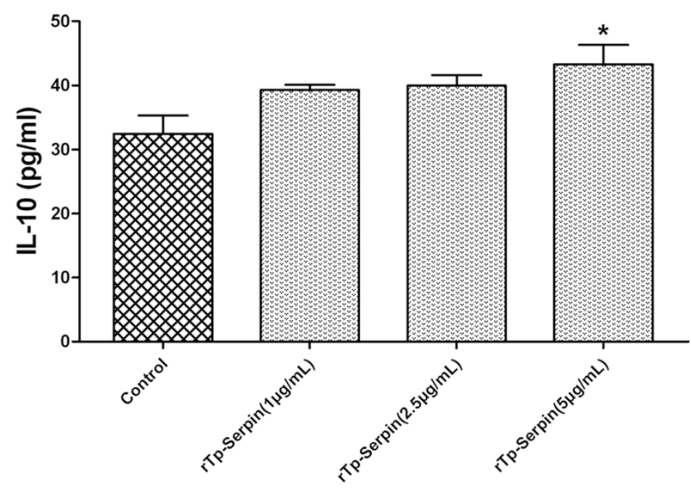

FIGURE 6 | Analysis of phosphorylation in JAK2/STAT3 signaling pathway and the expression levels of IL-10 in the early period of M2 polarization after treatment with rTp-Serpin. (A) Western bolt analysis of phosphorylation in JAK2 and STAT3 after treatment with different concentrations of $r T p$-Serpin (1-5 $\mu \mathrm{g} / \mathrm{ml})$.

(B) Expression levels of IL-10 in the early period of M2 polarization. Results are shown as the mean \pm SD for at least three repeated experiments for each group. Significant differences are as follows: $* p<0.05 ; * *<0.01$.

M2 polarization, the types of cytokines and effector molecules in macrophages are changed, and leading to anti-inflammatory and tissue repair effects (Kreider et al., 2007; Lumeng et al., 2007; Killock, 2011; Lim et al., 2016; Bosurgi et al., 2017). Similarly, previous studies have shown that Arg1 can inhibit the pro-inflammatory function of iNOS. In our study, we tested the ability of $\mathrm{rTp}$-Serpin to induce macrophage polarization by incubation with murine J774A.1 macrophages alone or co-treatment with LPS. As expected, M2 polarization and inhibition of LPS-induced M1 polarization were confirmed by the percentage changes in $\mathrm{CD}_{206^{+}}(\mathrm{M} 2)$ or $\mathrm{CD} 16 / 32^{+}$(M1) cells, respectively. Furthermore, the transcription and expression of anti-inflammatory cytokines and functional molecules of M2 (Arg1) were up-regulated by rTp-Serpin alone. On the other hand, pro-inflammatory cytokines and iNOS induced by LPS were suppressed, indicating that $\mathrm{rTp}$-Serpin inhibited macrophage polarization to the M1 phenotype by co-treatment with LPS. Taken together, these results suggest that $\mathrm{rTp}$ Serpin alone could induce M2 polarization. Similarly, rTp-Serpin inhibited M1 polarization caused by LPS in vitro.

In the process of M2 polarization and helminth infection, the immune response of the host to helminth infections is strikingly dominated by a Th2 response with a significant production of IL-4, IL-10, IL-13 (Pulendran and Artis, 2012), and the STAT3/STAT6 signaling pathways have been detected (O'Shea et al., 2002; Schindler et al., 2007). Unlike T. spiralis and most other helminths, T. pseudospiralis induces strong immunosuppression and inhibits both Th1 and Th2 immune responses (Dvoroznakova et al., 2011), in which the IL-4/STAT6 signaling pathway does not have such an effect. Simultaneously, high levels of IL-10 were also detected locally (Bastos et al., 2002; Beiting et al., 2007). Consistent with previous results, all pro-inflammatory cytokines levels in macrophages treated with LPS, including IL-1 $\beta$ (Ip et al., 2017), were suppressed by rTp-Serpin, which implies that the alternation of macrophage polarization induced by $\mathrm{rTp}$-Serpin may be IL-4/STAT6independent in vitro. Unlike other Th2 cytokines, the IL-10 signaling pathway recruits Jak2 followed by phosphorylation of tyrosine in STAT3, and induces the expression of the suppressor of cytokine signaling (SOCS3), which can reduce the expression of a variety of cytokines (Nakamura et al., 2015). Combined with the inhibition of macrophage pro-inflammatory cytokines, STAT3 was found to be responsible for the effect of pro-inflammatory cytokine suppression by Western blot analysis. Since phosphorylation of STAT3 was detected earlier than an increase in IL-10, $\mathrm{rTp}$-Serpin may activate other receptors to phosphorylate STAT3 in an IL-10R-independent method in vitro, which needs to be confirmed in further study.

\section{CONCLUSION}

We have determined that $\mathrm{rTp}$-Serpin could effectively inhibit the immune response by inhibiting the hydrolytic activity of immune-related proteases in vitro. M2 polarization was confirmed by flow cytometry and the up-regulation of M2associated genes (cytokines and effector molecules) through STAT3 signaling pathway activation was also confirmed. Moreover, Tp-Serpin inhibited LPS-induced M1 polarization by inhibition of pro-inflammatory cytokines. Although the immunoregulatory activity requires further verification in vivo, it appears that $\mathrm{rTp}$-Serpin may play an important role in the regulation of $T$. pseudospiralis infection by macrophage polarization. Furthermore, we believe that $T p$-Serpin may have the potential to reduce damage in autoimmune diseases.

\section{AUTHOR CONTRIBUTIONS}

NX analyzed data and wrote the paper; $\mathrm{XB}$ and $\mathrm{XL}$ designed the research; XL, BT, LW, HS, and PB performed the experiments; 
ML approved the version to be published; and all authors read and approved the final manuscript.

\section{FUNDING}

This study was supported by The National Key Research and Development Program of China (2017YFD0501302, 2016YFD0500707), China Postdoctoral Science Foundation funded project (2015T80310), National Nature Science

\section{REFERENCES}

Arora, N., Tripathi, S., Singh, A. K., Mondal, P., Mishra, A., and Prasad, A. (2017). Micromanagement of immune system: role of miRNAs in helminthic infections. Front. Microbiol. 8:586. doi: 10.3389/fmicb.2017.00586

Asano, K., Wu, Z., Srinontong, P., Ikeda, T., Nagano, I., Morita, H., et al. (2016). Nonencapsulated Trichinella pseudospiralis infection impairs follicular helper $\mathrm{T}$ cell differentiation with subclass-selective decreases in antibody responses. Infect. Immun. 84, 3550-3556. doi: 10.1128/IAI.00597-16

Bai, X., Wu, X., Wang, X., Guan, Z., Gao, F., Yu, J., et al. (2012). Regulation of cytokine expression in murine macrophages stimulated by excretory/secretory products from Trichinella spiralis in vitro. Mol. Cell. Biochem. 360, 79-88. doi: 10.1007/s11010-011-1046-4

Bank, U., and Ansorge, S. (2001). More than destructive: neutrophil-derived serine proteases in cytokine bioactivity control. J. Leukoc. Biol. 69, 197-206.

Bastos, K. R., Alvarez, J. M., Marinho, C. R., Rizzo, L. V., and Lima, M. R. (2002). Macrophages from IL-12p40-deficient mice have a bias toward the M2 activation profile. J. Leukoc. Biol. 71, 271-278.

Beiting, D. P., Gagliardo, L. F., Hesse, M., Bliss, S. K., Meskill, D., and Appleton, J. A. (2007). Coordinated control of immunity to muscle stage Trichinella spiralis by IL-10, regulatory T cells, and TGF-beta. J. Immunol. 178, 1039-1047. doi: 10.4049/jimmunol.178.2.1039

Biswas, S. K., and Mantovani, A. (2010). Macrophage plasticity and interaction with lymphocyte subsets: cancer as a paradigm. Nat. Immunol. 11, 889-896. doi: 10.1038/ni.1937

Boonmars, T., Wu, Z., Nagano, I., and Takahashi, Y. (2005). Trichinella pseudospiralis infection is characterized by more continuous and diffuse myopathy than T. spiralis infection. Parasitol. Res. 97, 13-20. doi: 10.1007/ s00436-005-1359-x

Bosurgi, L., Cao, Y. G., Cabeza-Cabrerizo, M., Tucci, A., Hughes, L. D., Kong, Y., et al. (2017). Macrophage function in tissue repair and remodeling requires IL-4 or IL-13 with apoptotic cells. Science 356, 1072-1076. doi: 10.1126/science. aai8132

Bruschi, F. (2002). The immune response to the parasitic nematode Trichinella and the ways to escape it. From experimental studies to implications for human infection. Curr. Drug. Targets Immune Endocr. Metabol. Disord. 2, 269-280. doi: $10.2174 / 1568008023340523$

Bruschi, F., Bianchi, C., Fornaro, M., Naccarato, G., Menicagli, M., GomezMorales, M. A., et al. (2014). Matrix metalloproteinase (MMP)-2 and MMP-9 as inflammation markers of Trichinella spiralis and Trichinella pseudospiralis infections in mice. Parasite Immunol. 36, 540-549. doi: 10.1111/pim.12138

Cwiklinski, K., Meskill, D., Robinson, M. W., Pozio, E., Appleton, J. A., and Connolly, B. (2009). Cloning and analysis of a Trichinella pseudospiralis muscle larva secreted serine protease gene. Vet. Parasitol. 159, 268-271. doi: 10.1016/j. vetpar.2008.10.036

Dvoroznakova, E., Hurnikova, Z., and Kolodziej-Sobocinska, M. (2011). Development of cellular immune response of mice to infection with low doses of Trichinella spiralis, Trichinella britovi and Trichinella pseudospiralis larvae. Parasitol. Res. 108, 169-176. doi: 10.1007/s00436-010-2049-x

Gordon, S. (2003). Alternative activation of macrophages. Nat. Rev. Immunol. 3, 23-35. doi: 10.1038/nri978

Gottstein, B., Pozio, E., and Nockler, K. (2009). Epidemiology, diagnosis, treatment, and control of trichinellosis. Clin. Microbiol. Rev. 22, 127-145. doi: 10.1128/ CMR.00026-08
Foundation of China (NSFC 31520103916, NSFC 31402185), and Guangdong Innovative and Enterpreneurial Research Team Program (no. 2014ZT05S123).

\section{ACKNOWLEDGMENTS}

We thank Xinrui Wang for the technical assistance. Our thanks are also extended to express our gratitude to all the people who made this work.

Heit, C., Jackson, B. C., McAndrews, M., Wright, M. W., Thompson, D. C., Silverman, G. A., et al. (2013). Update of the human and mouse SERPIN gene superfamily. Hum. Genomics 7:22. doi: 10.1186/1479-7364-7-22

Ilic, N., Gruden-Movsesijan, A., and Sofronic-Milosavljevic, L. (2012). Trichinella spiralis: shaping the immune response. Immunol. Res. 52, 111-119. doi: 10.1007/ s12026-012-8287-5

Ip, W., Hoshi, N., Shouval, D. S., Snapper, S., and Medzhitov, R. (2017). Anti-inflammatory effect of IL-10 mediated by metabolic reprogramming of macrophages. Science 356, 513-519. doi: 10.1126/science.aal3535

Kang, J. M., Sohn, W. M., Ju, J. W., Kim, T. S., and Na, B. K. (2010). Identification and characterization of a serine protease inhibitor of Clonorchis sinensis. Acta. Trop. 116, 134-140. doi: 10.1016/j.actatropica.2010.06.007

Killock, D. (2011). Connective tissue diseases: SAP-induced macrophage polarization: a potential therapeutic option for SLE? Nat. Rev. Rheumatol. 7, 497. doi: 10.1038/nrrheum.2011.113

Kim, E. M., Kwak, Y. S., Yi, M. H., Kim, J. Y., Sohn, W. M., and Yong, T. S. (2017). Clonorchis sinensis antigens alter hepatic macrophage polarization in vitro and in vivo. PLOS Negl. Trop. Dis. 11:e5614. doi: 10.1371/journal.pntd. 0005614

Kreider, T., Anthony, R. M., Urban, J. J., and Gause, W. C. (2007). Alternatively activated macrophages in helminth infections. Curr. Opin. Immunol. 19, 448-453. doi: 10.1016/j.coi.2007.07.002

Lim, M. P., Firdaus-Raih, M., and Nathan, S. (2016). Nematode peptides with host-directed anti-inflammatory activity rescue Caenorhabditis elegans from a Burkholderia pseudomallei infection. Front. Microbiol. 7:1436. doi: 10.3389/ fmicb.2016.01436

Lumeng, C. N., Bodzin, J. L., and Saltiel, A. R. (2007). Obesity induces a phenotypic switch in adipose tissue macrophage polarization. J. Clin. Invest. 117, 175-184. doi: 10.1172/JCI29881

Miller, H. R., and Pemberton, A. D. (2002). Tissue-specific expression of mast cell granule serine proteinases and their role in inflammation in the lung and gut. Immunology 105, 375-390. doi: 10.1046/j.1365-2567.2002.01375.x

Molehin, A. J., Gobert, G. N., Driguez, P., and McManus, D. P. (2014). Characterisation of a secretory serine protease inhibitor ( $\mathrm{SjB} 6$ ) from Schistosoma japonicum. Parasit. Vectors 7:330. doi: 10.1186/1756-33057-330

Molehin, A. J., Gobert, G. N., and McManus, D. P. (2012). Serine protease inhibitors of parasitic helminths. Parasitology 139, 681-695. doi: 10.1017/ S0031182011002435

Moreira, C. J., Waniek, P. J., Valente, R. H., Carvalho, P. C., Perales, J., Feder, D., et al. (2014). Isolation and molecular characterization of a major hemolymph serpin from the triatomine, Panstrongylus megistus. Parasit. Vectors 7:23. doi: 10.1186/1756-3305-7-23

Nagano, I., Wu, Z., Nakada, T., Boonmars, T., and Takahashi, Y. (2003). Molecular cloning and characterization of a serine proteinase gene of Trichinella spiralis. J. Parasitol. 89, 92-98.

Nagano, I., Wu, Z., Nakada, T., Matsuo, A., and Takahashi, Y. (2001) Molecular cloning and characterization of a serine proteinase inhibitor from Trichinella spiralis. Parasitology 123, 77-83. doi: 10.1017/S0031182001 008010

Nakamura, R., Sene, A., Santeford, A., Gdoura, A., Kubota, S., Zapata, N., et al. (2015). IL10-driven STAT3 signalling in senescent macrophages promotes pathological eye angiogenesis. Nat. Commun. 6:7847. doi: 10.1038/ ncomms 8847 
O'Shea, J. J., Gadina, M., and Schreiber, R. D. (2002). Cytokine signaling in 2002: new surprises in the Jak/Stat pathway. Cell 109(Suppl.), S121-S131. doi: 10.1016/S0092-8674(02)00701-8

Park, H. K., Cho, M. K., Choi, S. H., Kim, Y. S., and Yu, H. S. (2011). Trichinella spiralis: infection reduces airway allergic inflammation in mice. Exp. Parasitol. 127, 539-544. doi: 10.1016/j.exppara.2010.10.004

Pozio, E., and Zarlenga, D. S. (2013). New pieces of the Trichinella puzzle. Int. J. Parasitol. 43, 983-997. doi: 10.1016/j.ijpara.2013.05.010

Pulendran, B., and Artis, D. (2012). New paradigms in type 2 immunity. Science 337, 431-435. doi: 10.1126/science.1221064

Ramanan, D., Bowcutt, R., Lee, S. C., Tang, M. S., Kurtz, Z. D., Ding, Y., et al. (2016). Helminth infection promotes colonization resistance via type 2 immunity. Science 352, 608-612. doi: 10.1126/science.aaf3229

Reichard, M. V., Criffield, M., Thomas, J. E., Paritte, J. M., Cunningham, M., Onorato, D., et al. (2015). High prevalence of Trichinella pseudospiralis in Florida panthers (Puma concolor coryi). Parasit. Vectors 8, 67. doi: 10.1186/ s13071-015-0674-z

Robinson, M. W., Greig, R., Beattie, K. A., Lamont, D. J., and Connolly, B. (2007). Comparative analysis of the excretory-secretory proteome of the muscle larva of Trichinella pseudospiralis and Trichinella spiralis. Int. J. Parasitol. 37, 139-148. doi: 10.1016/j.ijpara.2006.08.007

Rostami, A., Gamble, H. R., Dupouy-Camet, J., Khazan, H., and Bruschi, F. (2017). Meat sources of infection for outbreaks of human trichinellosis. Food Microbiol. 64, 65-71. doi: 10.1016/j.fm.2016.12.012

Schindler, C., Levy, D. E., and Decker, T. (2007). JAK-STAT signaling: from interferons to cytokines. J. Biol. Chem. 282, 20059-20063. doi: 10.1074/jbc. R700016200

Sofronic-Milosavljevic, L., Ilic, N., Pinelli, E., and Gruden-Movsesijan, A. (2015). Secretory products of Trichinella spiralis muscle larvae and immunomodulation: implication for autoimmune diseases, allergies, and malignancies. J. Immunol. Res. 2015:523875. doi: 10.1155/2015/52 3875

Sudduth, T. L., Greenstein, A., and Wilcock, D. M. (2013). Intracranial injection of Gammagard, a human IVIg, modulates the inflammatory response of the brain and lowers Abeta in APP/PS1 mice along a different time course than anti-Abeta antibodies. J. Neurosci. 33, 9684-9692. doi: 10.1523/JNEUROSCI.1220-13. 2013

Tang, B., Liu, M., Wang, L., Yu, S., Shi, H., Boireau, P., et al. (2015). Characterisation of a high-frequency gene encoding a strongly antigenic cystatin-like protein from Trichinella spiralis at its early invasion stage. Parasit. Vectors. 8, 78. doi: 10.1186/s13071-015-0689-5

Wang, S., Xie, Y., Yang, X., Wang, X., Yan, K., Zhong, Z., et al. (2016). Therapeutic potential of recombinant cystatin from Schistosoma japonicum in TNBSinduced experimental colitis of mice. Parasit. Vectors 9, 6. doi: 10.1186/s13071015-1288-1

Zhang, Z., Mao, Y., Li, D., Zhang, Y., Li, W., Jia, H., et al. (2016). Highlevel expression and characterization of two serine protease inhibitors from Trichinella spiralis. Vet. Parasitol. 219, 34-39. doi: 10.1016/j.vetpar.2016.02.003

Conflict of Interest Statement: The authors declare that the research was conducted in the absence of any commercial or financial relationships that could be construed as a potential conflict of interest.

Copyright (c) 2017 Xu, Liu, Tang, Wang, Shi, Boireau, Liu and Bai. This is an open-access article distributed under the terms of the Creative Commons Attribution License (CC BY). The use, distribution or reproduction in other forums is permitted, provided the original author(s) or licensor are credited and that the original publication in this journal is cited, in accordance with accepted academic practice. No use, distribution or reproduction is permitted which does not comply with these terms. 